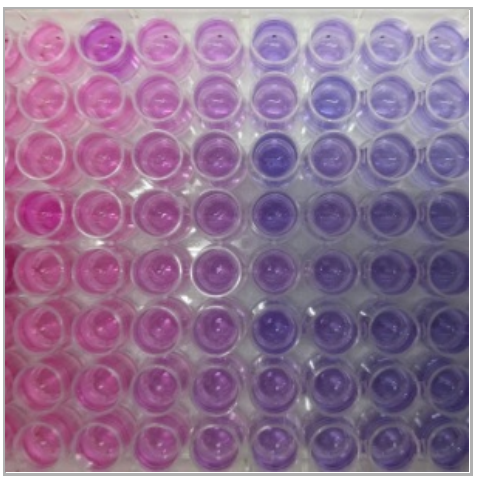

JUN 10, 2018

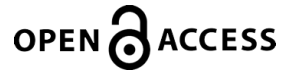

DOI:

dx.doi.org/10.17504/protocol s.io.quwdwxe

Protocol Citation: Bulent Arman Aksoy, Pınar Aksoy, Jeff Hammerbacher 2018. Resazurin viability assay for human primary T cells in 96well format. protocols.io https://dx.doi.org/10.17504/p rotocols.io.quwdwxe

License: This is an open access protocol distributed under the terms of the Creative Commons Attribution License, which permits unrestricted use, distribution, and reproduction in any medium, provided the original author and source are credited

Protocol status: Working We use this protocol and it's working

Created: Jun 10, 2018

Last Modified: Jun 10, 2018

PROTOCOL integer ID: 12918

\section{(3) Resazurin viability assay for human primary T cells in 96-well format}

In 6 collections

\author{
Bulent Arman Aksoy ${ }^{1}$, Pınar Aksoy ${ }^{1}$, Jeff Hammerbacher ${ }^{1}$ \\ ${ }^{1}$ Medical University of South Carolina \\ Hammer Lab

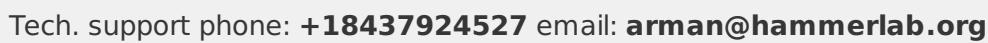

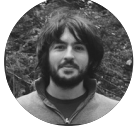

\section{Bulent Arman Aksoy}

Medical University of South Carolina

\section{GUIDELINES}

- Always make sure you have at least 4 replicates

- Always make sure to have blank media control (ideally on the same plate but having another plate with only media in it is $\mathrm{OK}$, too)

- Plate readers are relatively less accurate for the most outer wells so do not use them specifically for a condition alone (it might bias your results). Having a replicate for each of your conditions in either of the most outer wells is OK.

- It is much easier to work in batches via multichannel pipettors and make use of the reagent cuvette

- The dye is sensitive to light/temperature. No need to go crazy about this but make sure you don't leave the plate out for more than 10 minutes before measuring

- Do not go over $200 \mathrm{ul}$ in total when preparing your cultures

- Plan carefully and remember to add the dye a day (24 hours) before your endpoint assay

- The assay is not that accurate $>300,000$ cells per well or $<1,000$ cells per well so make sure you seed the cells in such a way that you will hit the reliable cell counts on the day of your measurement

\section{MATERIALS}

MATERIALS

88 PBS Contributed by users

88 Resazurin sodium salt Millipore Sigma Catalog \#R7017

8 alamarBlue $^{\text {TM }}$ Cell Viability Reagent Thermo Fisher Scientific Catalog \#DAL1025 


\section{BEFORE START INSTRUCTIONS}

Pre-made Alamar Blue (Resazurin) solutions from companies (e.g. alamarBlue ${ }^{\mathrm{TM}}$ Cell Viability Reagent) are relatively expensive for long-term and common use.

Therefore, ordering it in powder format is the cheapest and the most feasible way to go for extended use cases. $1 \mathrm{~g}$ powder (e.g. Resazurin sodium salt \#R7017) should last for a year or two even if it is frequently used.

The final working concentration for Resazurin is $44 \mathrm{uM}$ and our goal is to prepare a $10 \mathrm{X}$ solution for use in cell culture (e.g. for $200 \mathrm{ul}$ of media/cells, we will add 20 ul of the dye). Directly preparing this is not feasible (due to the amount of PBS required) so we will first prepare a 1000X stock solution which we will further dilute as needed.

For $1000 \times$ Stock (44 mM):

- Weigh 5 gram of Resazurin powder

- Resolve the powder in $500 \mathrm{ml} \mathrm{PBS} \mathrm{(this} \mathrm{will} \mathrm{require} \mathrm{vigorous} \mathrm{shaking/mixing} \mathrm{for} \mathrm{a}$ few times so make sure you don't have any residues in the solution)

- Sterile filter the solution and prepare 10 aliquots (each $50 \mathrm{ml}$ )

- Store the $1000 \mathrm{X}$ stocks at $-20^{\circ} \mathrm{C}$ (either wrap each one with aluminum foil or use a cardboard box to limit light exposure for long term)

For $10 \times$ Stock (440 uM):

- Add 500 ul of $1000 X$ stock onto $50 \mathrm{ml}$ of PBS in a falcon tube (usually makes sense to prepare 4-5 of these)

- Wrap the falcon tube with aluminum foil so that it is minimally exposed to sunlight

- Store $10 \mathrm{X}$ working solutions at $4^{\circ} \mathrm{C}$ (they should be good for up to 6 months)

- Can also store one $1000 \mathrm{X}$ stock at $4^{\circ} \mathrm{C}$ for convenience (if planning to assay frequently)

1 Add 10X dye for each well using a multichannel pipettor (so, for 200 ul you will be adding 20 ul of the $10 \mathrm{X}$ solution)

2 Continue culturing the cells the same way for 24 hours

(3) $24: 00: 00$

3 Use a plate reader to measure the absorbance at both $570 \mathrm{~nm}$ and $595 \mathrm{~nm}$ 


\section{Equipment}

BIO-RAD

$4 \quad$ Subtract your $595 \mathrm{~nm}$ measurement from the $570 \mathrm{~nm}$ for each well

5 Then (optionally) subtract your blank media measurement from your treatment measurements

6 The number you end up is directly proportional to the number of cells in the well. 